\title{
BANGUNAN KANTOR MULTIFUNGSI DI TANAH ABANG
}

\author{
Annissa Nur Sofura ${ }^{1)}$, Petrus Rudi Kasimun ${ }^{21}$ \\ 1)Program Studi S1 Arsitektur, Fakultas Teknik, Universitas Tarumanagara, annissanurs@gmail.com \\ 2)Program Studi S1 Arsitektur, Fakultas Teknik, Universitas Tarumanagara, rudi.kasimun@gmail.com
}

\begin{abstract}
Abstrak
Generasi milenial masih menjadi topik yang sangat hangat diperbincangkan. Banyaknya permasalahan pada generasi ini menjadikan sebagian besar manusia meneliti dan mencari cara untuk mengatasi hal-hal tersebut. Pada kesempatan kali ini, permasalahan dari generasi milenial yang akan akan dipilih untuk diselesaikan dengan produk arsitektur yaitu berupa usia produktif. Usia produktif tersebut melatarbelakangi aktivitas utama generasi milenial berupa bekerja. Banyak juga penelitian yang mengatakan bahwa pekerjaan tersebut menjadi penyebab terjadinya tingkat stress tertinggi terjadi pada generasi ini. Setelah di teliti lebih dalam, bukan karena harus bekerja yang menjadi alasan utama tingkat stress terjadi pada milenial, melainkan kondisi dan sistem kerja yang tidak sesuai dengan kriteria generasi tersebut. Oleh karena itu, program "kantor" akan menjadi jalan keluarnya. Kantor yang akan dibuat akan dibagi menjadi dua tipe, yaitu kantor sewa yang dibangun dengan bentuk bangunan tinggi dengan sistem penyewaan per-lantai, dan co-working space yang dibangun dengan bentuk bangunan rendah dengan sistem penyewaan per-ruang. Untuk mendukung program utama berupa kantor maka akan diusulkan pula program penunjang. Proyek ini akan dibuat dengan metode tipologi, dimana prosesnya akan melalui tahap analisa pada beberapa aspek yang digunakan oleh bangunan - bangunan kantor terdahulu dan dilihat bagaimana perkembangannya terhadap bangunan kantor hingga tahun 2019. Konsep utama bangunan ini akan mengarah pada "icon" atau bisa disebut monumental, dan diharapkan dapat memperlihatkan bentuk bangunan milenial.
\end{abstract}

Kata kunci: kantor; milenial; monumental; produktif; tipologi

\begin{abstract}
Millennials is still a very hot topic to discuss. The many problems in this generation make most people research and find ways to overcome these things. On this occasion, the millennial generation problem that will be chosen to be solved with architectural products is the productive age. This productive age is the background of the main activity of the millennial generation, which is working. Many studies also say that this work is the cause of the highest level of stress occurring in this generation. After being examined more deeply, not because it has to work which is the main reason for the stress level to occur in millennials, but the conditions and work systems that are not in accordance with the criteria of that generation. Therefore, the "office" program will be the solution. The office to be created will be divided into two types, namely the rental office built in the form of a high-rise building with a per-floor rental system, and a co-working space built in the form of a low-rise building with a per-room rental system. To support the main program in the form of an office, supporting programs will also be proposed. This project will be made using a typology method, where the process will go through an analysis phase on several aspects used by the previous office buildings and see how it will develop to office buildings until 2019. The main concept of this building will be "icon" or monumental, and is expected to show the shape of millennial buildings.
\end{abstract}

Keywords : millennial; monumental; office; productive; typology 


\section{PENDAHULUAN}

Generasi milenial menjadi penyumbang populasi manusia terbesar di Indonesia. Hal ini menyebabkan banyak yang memberikan perhatian berlebih pada generasi ini. Generasi Milenial atau Generasi Y ini selalu dikaitkan dengan IT (Information Technology) dan IOT (Internet of Things), dimana sebuah zaman berubah menjadi serba cepat dan instan dengan adanya perkembangan teknologi. Minat dan bakat terbesar pada generasi ini juga mengarah pada bidang IT, atau social media developer. Sebagian besar dari perusahaan yang bergerak dibidang social media developer memilih untuk menyewa ruang pada suatu bangunan untuk dijadikan kantor atau tempat mereka bekerja. Alasannya adalah kemudahan yang ditawarkan pada proses penyewaan bila dibandingan dengan membangun bangunan tunggal. Sebuah kantor sewa juga dinilai memiliki efektifitas yang lebih baik karena penyusunan ruang dan furnitur bisa disesuaikan dengan keinginan penyewa, dimana targetnya kali ini adalah milenial. Selain itu, perusahaan start-up akan memilih ruangan yang lebih kecil untuk menampung karyawannya dan biasanya yang disewa adalah bilik pada area co-working space. Oleh karena itu, perhatian utama pada proyek ini adalah kantor sewa dan co-working space.

Lokasi yang dipilih yaitu di kecamatan Tanah Abang khususnya di Jalan Teluk Betung I. Lokasi ini dipilih berdasarkan tiga kriteria, pertama adalah pusat kota dimana jaraknya akan lebih dekat bila diakses dari titik-titik lain di Jakarta. Kedua yaitu transportasi umum yang sangat memadai. Ketiga yaitu lokasinya berdekatan dengan area komersil, hal ini merupakan salah satu kriteria kantor idaman dari generasi milenial. Desain yang akan dibuat akan memiliki konsep atau sosok monumental, dimana bangunan ini nantinya tidak akan memiliki bentuk seperti bangunan disekitarnya (tidak kontekstual). Lalu sistem sewa yang diberlakukan adalah per-lantai dimana perbedaan luas pada tiap lantai yang disewakan akan terlihat pada fasad bangunan. Penempatan dan orientasi bangunan akan disesuaikan dengan hasil analisa tapak, dan untuk menciptakan bangunan yang ramah akan pengunjung selain karyawan yang bekerja di kantor (penyewa) maka nantinya lantai dasar akan dibuka secara keseluruhan (dan dibuat daerah hijau) dan program penunjang akan diletakkan tepat diatasnya. Sehingga alur yang diciptakan pada bangunan yaitu area hijau menuju area (program) penunjang lalu bercabang ke area kantor sewa dan co-working space.

\section{KAJIAN LITERATUR}

Milenial (atau generasi $Y$ ) adalah generasi yang kategorinya diukur berdasarkan tahun lahir, dan ada setelah generasi baby boomers atau generasi $X$. Topik mengenai millenial masih belum selesai dan masih diperdebatkan, sehingga acuan tahun lahir yang termasuk ke dalam generasi millenial juga masih berbeda-beda, jika di ambil titik tengah yaitu tahun 1985 hingga 1996 maka rentang umur yang masuk ke dalam kategori generasi millenial kurang lebih yaitu umur 23 - 34 tahun. Dalam data World Healt Organization (WHO), usia generasi milenial masuk dalam kategori usia produktif, dimana jika dilihat aktivitas utamanya adalah sekolah (pendidikan) dan bekerja. Umur paling tua pada generasi millenial dapat dikatakan masih jauh menuju usia pensiun (dimana standar yang ditentukan oleh UUD bahwa usia pensiun adalah 55 hingga 60 tahun), dan usia paling muda umumnya sudah memasuki masa akhir pendidikan, sehingga dapat dikatakan bahwa generasi millenial memerlukan lapangan pekerjaan.

Menurut hasil survey terbesar yang pernah dilakukan di Inggris mengenai kesehatan mental di dunia kerja, ditemukan jika $28 \%$ dari pekerja millenial mengaku mengalami stress. Riset yang dilakukan pada 5.632 orang ini pun mengungkap jika beban pekerjaan memang bisa sangat mempengaruhi kesehatan mental secara keseluruhan. Perwakilan Mental Health Foundation, Richard Grange mengatakan bahwa sebuah pekerjaan bagus dimana kita merasa aman dan didukung bisa mendorong kesehatan mental kita. Tapi kondisi kerja yang buruk dan tidak aman dapat mengacaukan kesehatan mental. Oleh sebab itu sebagai arsitek, saya akan mengusulkan program kantor yang dirancang untuk bisa mewadahi keinginan dan kriteria millenial. Adapula gaya arsitektur yang banyak disenangi oleh millenial yaitu sebagai berikut: 
- Memaksimalkan sumber daya kota dan efisien

- Fleksibelitas ruang dan furnitur

- Rapih dan sederhana

- Materi dan karakteristik alami

- Bahan bangunan hijau (eco-friendly)

- Smart teknologi

Jajak pendapat Gallup, atau lebih dikenal dengan Gallup Poll telah membuat laporan terbaru mengenai "How Millennials Want to Work and Live". Pada laporannya dikatakan bahwa ada "Enam Besar" perubahan fungsional dari keinginan lama ke keinginan baru yaitu:

- Milenium tidak hanya bekerja untuk gaji; mereka ingin tujuan. Bagi kaum milenial, pekerjaan harus memiliki makna. Mereka ingin bekerja organisasi dengan misi dan tujuan.

- Generasi Millenial tidak mengejar kepuasan kerja; mereka mengejar pengembangan. Sebagian besar milenium tidak peduli dengan lonceng dan peluit ditemukan di banyak tempat kerja hari ini - meja pingpong, latte mewah mesin dan makanan gratis yang ditawarkan perusahaan untuk mencoba menciptakan pekerjaan kepuasan.

- Milenium tidak menginginkan bos - mereka menginginkan pelatih. Peran seorang bos gaya lama adalah komando dan kontrol.

- Milenium tidak ingin ulasan tahunan; mereka ingin terus berlangsung percakapan.

- Milenium tidak ingin memperbaiki kelemahan mereka - mereka mau kembangkan kekuatan mereka. Gallup telah menemukan kelemahan itu tidak pernah berkembang menjadi kekuatan, sementara kekuatan berkembang tanpa batas.

- Ini bukan hanya pekerjaan saya - ini adalah hidup saya. Salah satu yang paling penting dari Gallup Penemuannya adalah bahwa setiap orang di dunia menginginkan pekerjaan yang baik. Ini adalah terutama berlaku untuk milenium.

Generasi milenial hidup di zaman teknologi yang sangat maju dan berkembang. Perilaku millenial dapat dikatakan identik dengan sesuatu yang cepat, praktis, dan digital. Dengan zaman yang berubah, maka kebiasaan dan tingkah laku generasi ini berbeda dari generasi sebelumnya, dimana faktanya milenial masih bekerja di kantor dengan gaya yang lama dan dengan sistem yang tidak sesuai, tingkat stress yang timbul pada generasi ini disebabkan dari hal tersebut.

Jika berbicara mengenai kantor, secara etimologis, kantor berasal dari serapan bahasa Belanda yaitu "kantoor". Kata kantoor dalam bahasa Belanda memiliki arti sebagai ruangan tempat bekerja, tempat instansi dan lain-lain. Kantor bisa pula diterjemahkan dalam bahasa Inggris "office" yang berarti tempat untuk memberikan pelayanan, atau ruang tempat bekerja. Menurut kamus besar bahasa Indonesia, kantor adalah balai (gedung, rumah, ruang) tempat mengurus suaru pekerjaan (perusahaan dan sebagainya). Kantor juga dapat dikatakan sebagai tempat bekerja. Ketika kita mengatakan "gedung kantor", kita berbicara tentang berbagai macam struktur. Kita dapat memaksudkan apa saja mulai dari bangunan pinggiran kota berlantai dua hingga bangunan tinggi perkotaan 100 lantai. Bangunan yang ada dalam pikiran kita dapat dibangun semata-mata berdasarkan spekulasi, untuk menampung apa pun yang penyewa pilih untuk ditempatkan di dalamnya, atau mungkin dibangun untuk memenuhi kebutuhan spesifik kantor pusat perusahaan. Apa pun ukuran atau jenisnya, gedung kantor adalah tipe bangunan yang kompleks dan dipengaruhi oleh banyak kekuatan. perannya yang paling penting adalah sebagai rumah bagi orang-orang yang bekerja di sana - bukan untuk mereka semua delapan jam sehari, tetapi mungkin empat atau mungkin dua belas jam - dan desainnya sangat memengaruhi kinerja mereka. 
Secara garis besar, menurut L. Manaseh dan R.Cunliffe, jenis kantor dapat dibedakan menjadi 4 jenis, yaitu:

- Commercial office

Jenis perkantoran yang termasuk golongan ini adalah perkantoran untuk toko,

disewakan, perusahaan trading company, asuransi, dan transportasi.

- Industrial office

Jenis perkantoran ini terikat dan harus mempunyai hubungan fisik dengan pabriknya.

- Professional office

Jenis perkantoran ini tidak dipakai dalam waktu yang panjang dan merupakan perkantoran dengan jumlah modal yang digunakan relatif kecil.

- Institutional Governmental office

Jenis perkantoran ini bersifat usaha yang teratur dalam bentuk lembaga yang

berpedoman pokok untuk hidup lama dan kokoh. Biasanaya digunakan dalam waktu yang lama atau panjang.

Maraknya dunia kewirausahaan digital di Indonesia pun mengindikasikan adanya kebutuhan bagi ruang kantor atau ruang bekerja alternatif. Karena karakter proses bekerjanya yang serba online, kantor tidak lagi harus berupa ruangan yang besar untuk menampung begitu banyak karyawan. Tidak sedikit pengusaha yang memulai bisnisnya dengan tim kecil ataupun bekerja dengan anggota tim di tempat berlainan karena adanya akses internet. Dunia bisnis semakin menyadari adanya kebutuhan berbeda bagi industri berbeda sehingga ruang kerja pun berbeda-beda bentuknya. Sekarang ini, ruang kerja tidak lagi terlihat begitu-begitu saja, ada berbagai macam jenis ruang kantor yang mulai populer, yaitu:

a. Virtual Office

Virtual office tidak benar-benar ada secara fisik. Yang ditawarkan adalah alamat surat dan poin kontak yang bisa dihubungi. Misalnya, sebuah startup menjalankan bisnisnya dari rumah, tetapi menyewa virtual office di gedung perkantoran. Maka, startup tersebut seakan beralamat di gedung perkantoran di mana virtual office berada. Jadi, walaupun startup dijalankan di rumah, bisnis tersebut akan tetap mendapatkan kredibilitas di antara pengguna potensialnya.Beberapa keuntungan komunikasi yang ditawarkan virtual office adalah resepsionis, asisten, call center, dan lainnya. Selain itu, ada juga space service, yang melibatkan alamat prestisius yang biasa ditawarkan sebuah virtual office. Servis ini memberikan alamat profesional, alamat surat, tempat meeting, dan kesempatan menyewa tempat untuk sementara waktu.

\section{b. Serviced Office}

Serviced Office bukan hanya menyediakan tempat tetapi juga segala pengurusnya. Sebuah manajemen fasilitas yang menjadi pengurusnya akan menyewakan ruangan kerja atau lantai kerja untuk beberapa perusahaan berbeda. Biasanya serviced office juga terletak di pusat bisnis di kota-kota besar. Tujuan dibentuknya ruang kantor serviced office adalah untuk memberikan fleksibilitas bagi pengusaha yang menggunakannya karenya biasanya dapat disewa dengan mudah. Biasanya, virtual office dan serviced office ditawarkan secara sepaket. Misalnya, CEO Suite, Voffice, dan Regus. Ketiganya adalah virtual office dan serviced office yang terletak di daerah prestisius Jakarta.

\section{c. Co-working Office}

Co working space adalah tempat di mana pengusaha dari bisnis yang berbeda dapat berbagi kantor. Biasanya, co-working space memiliki organisasi yang mengorganisir aktivitas di dalamnya. Ruang kerja seperti ini cocok untuk startup yang memiliki tim kurang dari enam orang, sehingga tidak sulit berbagi ruangan dengan tim-tim lain. Selain menjadi tempat bekerja yang kondusif, co-working space juga sering mengadakan event komunitas dan pengusaha, sehingga entrepreneur yang bekerja di dalamnya tidak hanya bekerja tetapi juga memperluas network. Untuk co-working space, di Jakarta tren ini telah mengambil perhatian banyak 
entrepreneur dan dunia startup. Beberapa co-working space yang bisa ditemukan di Jakarta adalah TierSpace, Ciputra GEPI Incubator, dan Kejora.

Bekerja di kantor masih menjadi impian bagi banyak orang termasuk kaum milenial. Meskipun begitu, kaum milenial yang aktif dan kreatif tidak memimpikan bekerja dengan seragam dan pergi ke kantor dari jam 8 pagi hingga 5 sore. Suasana dan lingkungan kerja yang nyaman menjadi sesuatu yang diidam-idamkan untuk menjadi kantor idaman kaum milenial saat ini. Kriteria kantor idaman kaum millennial lebih menekankan pada suasana yang nyaman dan fun untuk pribadi mereka yang kreatif dan dinamis. Meskipun kriteria Kantor Idaman kaum milenial berbeda dengan pendahulunya, tapi mereka juga tetap mengedepankan hard skill dan soft skill. Berikut ini beberapa kriteria kantor idaman kaum milenial.

- Akses internet yang cepat

Internet dan media sosial sudah menjadi kebutuhan utama yang setiap hari di konsumsi. Bila dieksekusi dengan baik, kemampuan media sosial dan internet bisa menjadi senjata utama perusahaan untuk semakin berkembang.

- Lingkungan kantor yang nyaman

Generasi milenial tidak terlalu menyukasi ruangan dengan desain yang formal dan kaku seperti ruang kerja yang terkotak-kotak. Desain ruangan yag lebih santai dengan bean bags di sudut-sudut kantor atau halaman hijau untuk menyegarkan mata menjadi salah satu gambaran kantor idaman generasi milenial.

- Jam kerja fleksibel

Bukan sebagai ajang bermalas-malasan, namun dengan jam kerja yang fleksibel, kaum milenial akan lebih menyeimbangkan antara pekerjaan dan kehidupan pribadi. Misalnya bisa ada kepentingan diluat kantor secara mendadak, karyawan diperbolehkan untuk pergi sebentar dan kembali lagi tanpa harus mengambil cuti.

- Fasilitas yang lengkap

Dengan fasilitas yang lengkap seperti internet, sarana relaksasi, dan sebagainya, akan membuat karyawan ingin untuk berlama-lama bekerja di kantor.

- Pekerjaan yang terhubung dengan kehidupan pribadi

Melalui pendekatan secara personal, perusahaan bisa lebih menilai kepribadian dan talenta karyawan, dengan begitu karyawan mempunyai kesempatan untuk berkarir sesuai dengan bakat mereka.

- Lokasi yang strategis

Generasi milenial lebih memilih kantor yang berlokasi strategis dan mempunyai kemudahan akses untuk berbagai urusan.

- Program pengembangan diri

Kaum millenial membutuhkan perusahaan yang mengapresiasi kinerja karyawan dan memberikan program pengembangan diri, sehingga karyawan mempunyai kesempatan untuk mengembangkan karir mereka ke jenjang yang lebih tinggi.

- Peraturan yang tidak kaku

Dengan pemikiran yang lebih dinamis dan terbuka, kaum milenial sudah tidak lagi menginginkan peraturan yang mengikat. Suasana kerja yang nyaman tidak akan berarti bila mereka tetap harus bekerja dengan seragam.

- Pressure yang sesuai dengan gaji

Tuntutan pekerjaan di era milenial saar ini cukup tinggi. Namun bila tekanan pekerjaan tidak sesuai dengan gaji maka akan membuat banyak karyawan yang mengundurkan diri. Bagi kaum milenial, tuntutan pekerjaan harus setara dengan gaji yang diterima.

Berdasarkan referensi di atas, maka bangunan yang dihasilkan nanti akan sesuai dengan kriteria dari generasi milenial, dimana jenis ruangnya akan berupa serviced office dan coworking space, lalu tatanan ruang akan memiliki sirkulasi yang bebas dan fleksibel, serta sistem yang diberikan kantor menjadi lebih bebas. 


\section{METODE}

Metode yang digunakan adalah metode perancangan tipologi. Tipologi merupakan kajian tentang tipe. Menurut Profesor Maldonado tipologi digunakan saat penyelesaian arsitektural yang berdasarkan program mengalami kesulitan, karena tidak semua dapat diamati dengan rinci, maka tipologi dapat membantu menyelesaikan masalah. Sedangkan menurut Aldo Rossi, tipologi arsitektur adalah obyek dan proses sekaligus. Bentuk-bentuk yang muncul menjadi tipe obyek sebagai pemulaan kreatif untuk menghasilkan obyek selanjutnya. Dalam ingatan kolektif, kita dapat menelusuri tipe. Metode tipologi yang kali ini digunakan prosesnya akan melalui tahap analisa pada beberapa aspek yang digunakan oleh bangunan-bangunan kantor terdahulu dan dilihat bagaimana perkembangannya terhadap bangunan kantor hingga tahun 2019. Setelah melalui tahap analisa makan hasilnya akan diterapkan pada proyek yang akan dirancang.

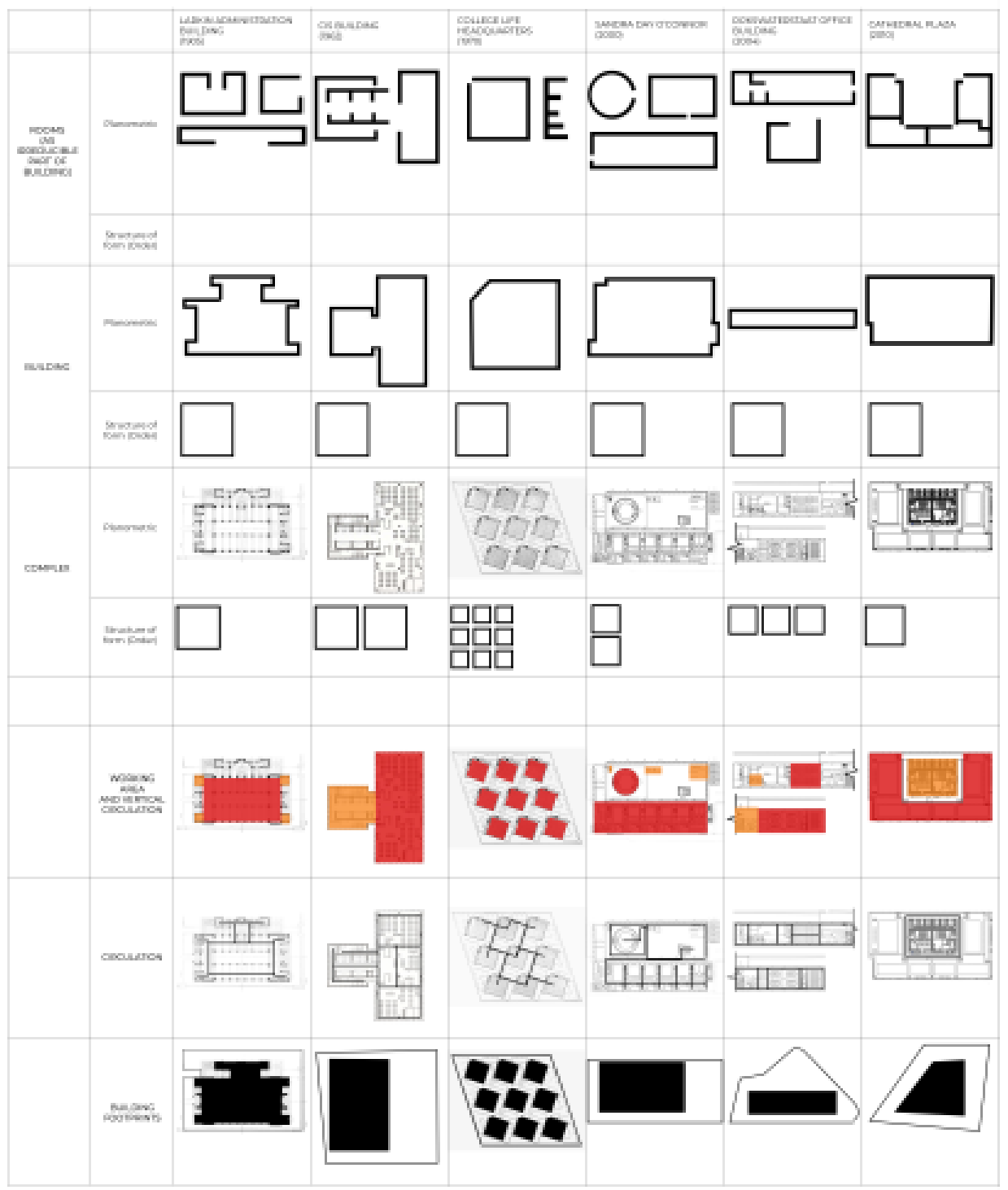

Gambar 1. Tipologi Bangunan Kantor Sumber: Penulis, 2019 


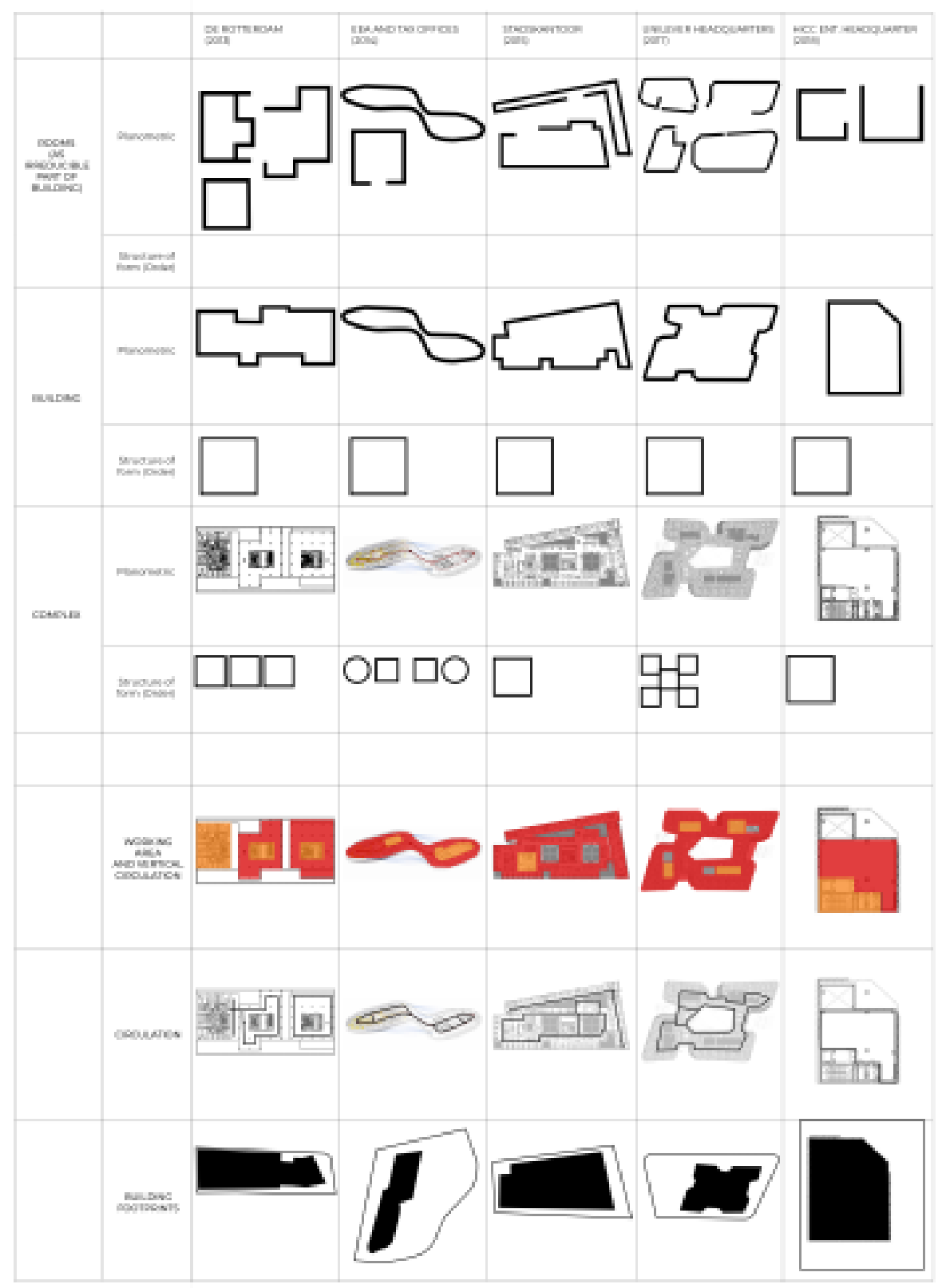

Gambar 2. Tipologi Bangunan Kantor

Sumber: Penulis, 2019

Dapat disimpulkan bahwa dari beberapa aspek pada setiap bangunan kantor tidak banyak berubah, yang terlihat berubah dengan sangat derastis hanya pada bagian denah dan sirkulasi, dimana seiring berkembangnya waktu maka bangunan kantor dibuat menjadi semakin fleksibel tanpa sekat. Hal ini dapat dikaitkan dengan pengguna kantor pada tahun 2018-2019 lebih banyak adalah generasi millenial, sehingga ruang yang tercipta memang terlihat lebih bebas dari tahun sebelum-sebelumnya, dimana penggunanya adalah generasi-generasi sebelum millenial.

\section{DISKUSI DAN HASIL}

Setelah melalui tahap analisa tipologi bangunan kantor lalu setelahnya masuk pada tahap menganalisa kawasan dan tapak perancangan proyek. Aspek- aspek yang dianalisa adalah yang berhubungan langsung terhadap pembangunan proyek seperti solid void area, ketinggian bangunan, bangunan sekitar, vegetasi, orientasi, drainase, kemacetan, view, dan akses. 


\section{ALLOTMENT, ACCESS, AND BUILDING HEIGHT}

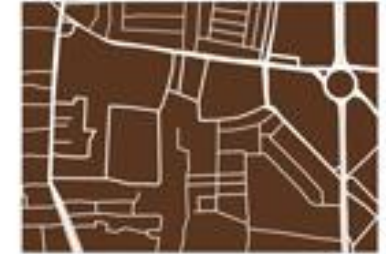

Solid Area

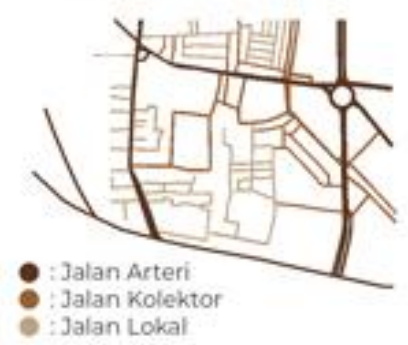

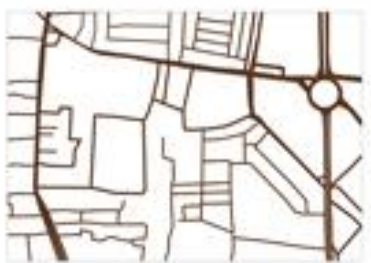

Void Area

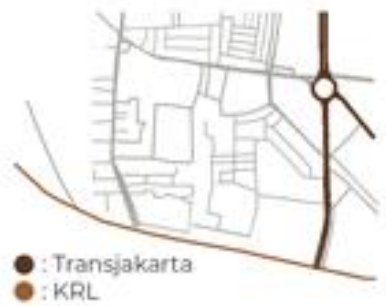

Gambar 3. Solid Void Area Sumber: Penulis, 2019

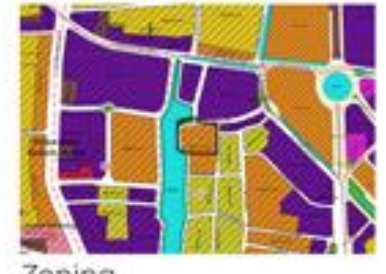

Zoning

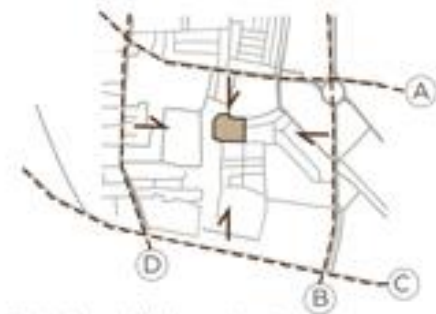

Peta kunci ketinggian bangunan

Gambar di atas menjelaskan area solid dan void pada kawasan sekitar tapak. Selain itu ada juga peraturan zonasi yang menjelaskan bahwa tapak masuk dalah zonasi campuran. Ada juga analisa hierarki jalan dan jalur transportasi umum untuk menjadi pertimbangan terhadap akses yang akan diberikan pada perancangan.

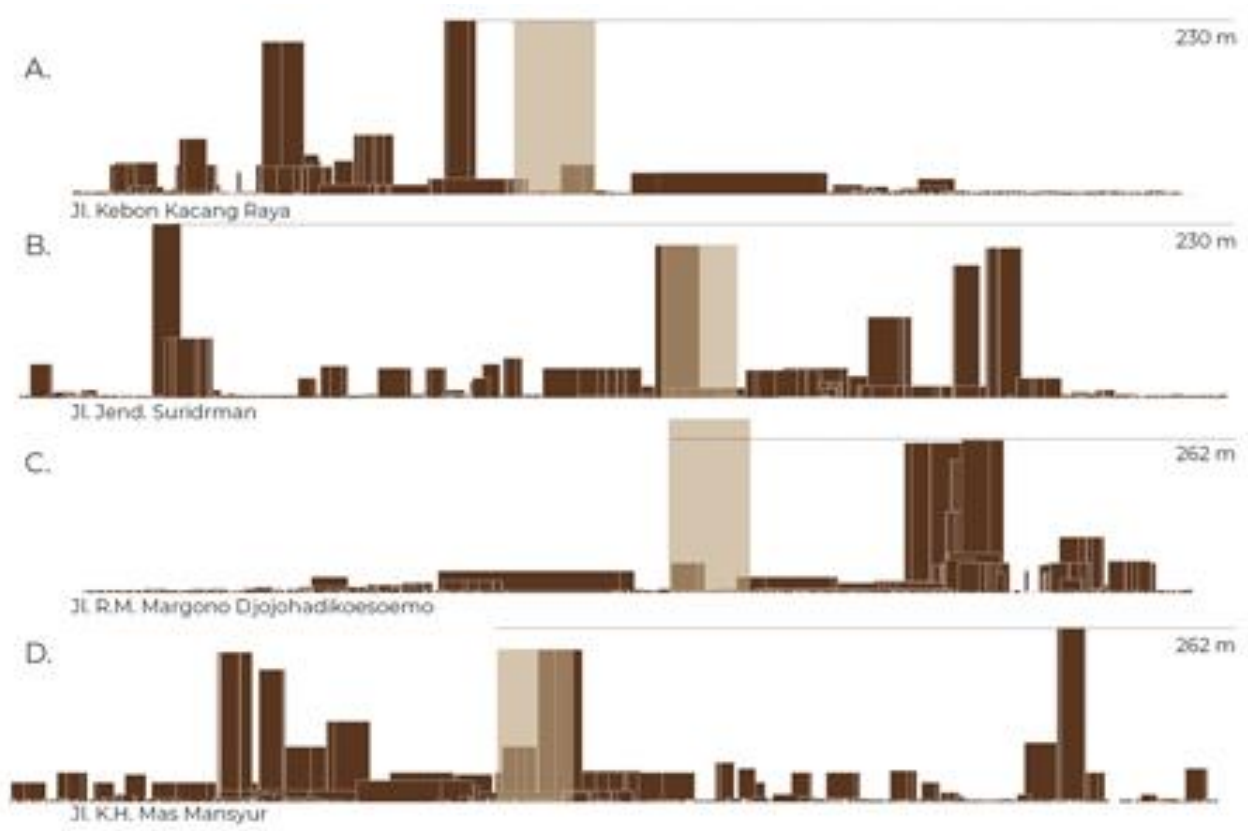

Gambar 4. Ketinggian Bangunan

Sumber: Penulis, 2019

Analisa ketinggian bangunan dilakukan dengan melihat skyline yang terbentuk dari bangunan - bangunan di sekitar tapak, dan melihat dimana sekiranya proyek akan terbangun sehingga tetap terlihat dari jalan besar dan mampu menjadi daya tarik untuk pengunjung. Sehingga menjadi penentu jumlah lantai yang akan dibangun agar bentuk skyline tetap menarik. 

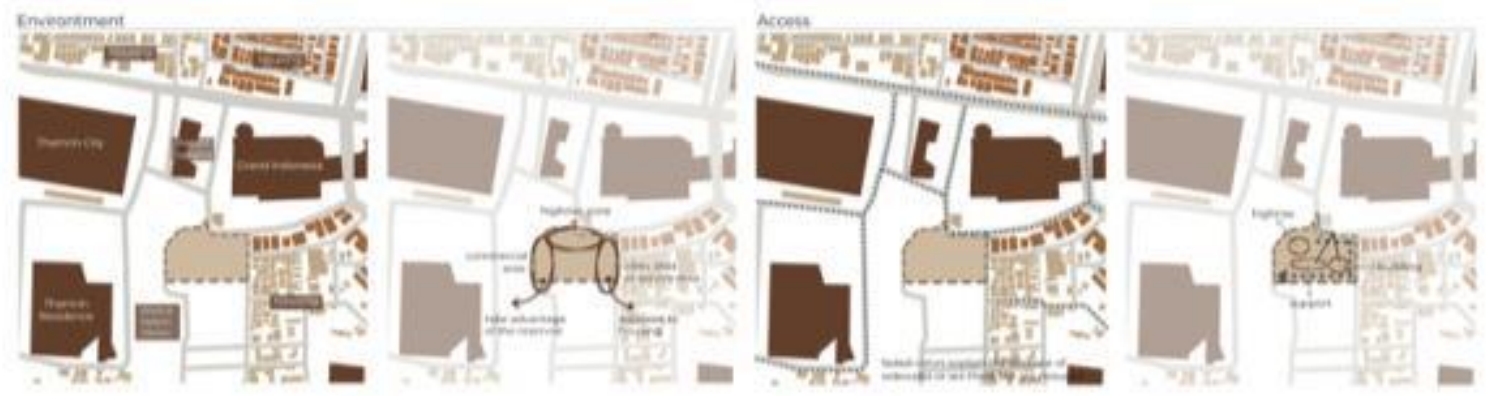

Gambar 5. Bangunan Sekitar dan Akses.

Sumber: Penulis, 2019

Bangunan sekitar menjadi pertimbangan dalam peletakan program pada tapak. Hal ini nantinya menjadi penentu yang hasilnya berupa peletakan area komersil dekat waduk dan terbuka, peletakan area highrise yang lebih condong ke arah depan sebagai point of view pada proyek, dan peletakan area servis di area kanan tapak karena berdekatan dengan perumahan. Lalu akses disini akan menjadi penentu peletakkan entrance atau pintu masuk utama pada bangunan. Hasilnya adalah area masuk akan diberikan pada sisi tapak yang berdekatan dengan jalan kolektor.
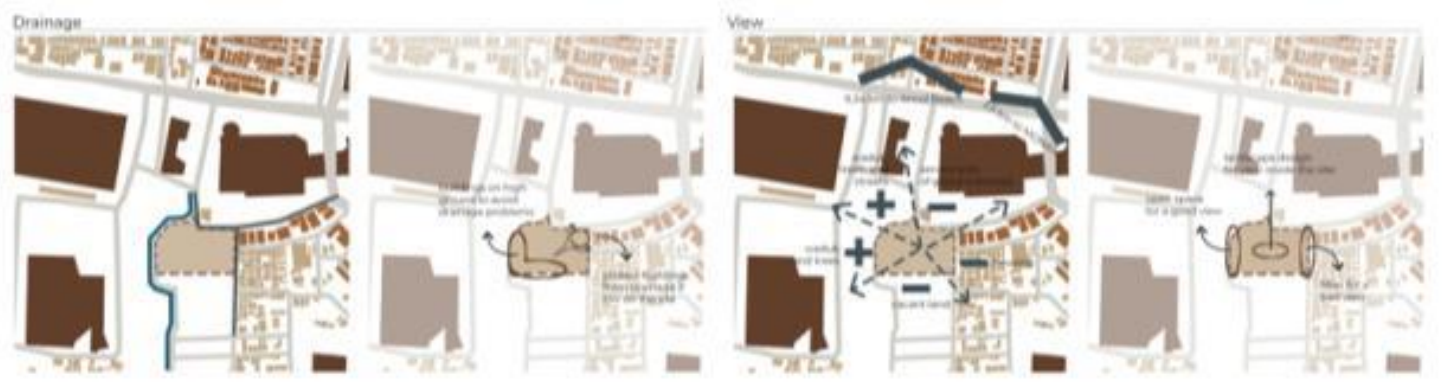

Gambar 6. Drainase dan View.

Sumber: Penulis, 2019

Drainase disini menjadi salah satu pertimbangan pada perancangan karena posisi tapak yang berdekatan dengan waduk, dimana waduk tersebut memiliki kemungkinan kecil untuk menguap. Oleh karena itu bangunan utama berupa tower akan diletakkan pada titik terjauh dari waduk. Lalu analisa view dibagi menjadi dua, yaitu untuk bangunan yang bersifat low-rise dan untuk bangunan yang bersifat highrise. Untuk area low-rise, view terbaik mengarah pada yang diberi tanda plus (+), dan untuk area highrise, view terbaik mengarah pada area yang diberi tanda panah besar.
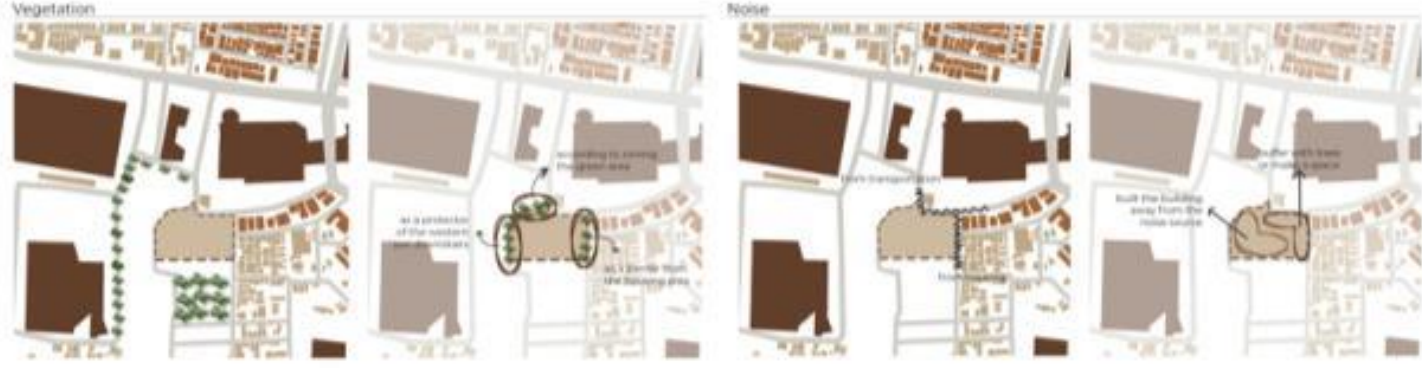

Gambar 7. Vegetasi dan Kebisingan.

Sumber: Penulis, 2019

Analisa vegetasi dilakukan untuk melihat area hijau yang berada di sekitar tapak, hal ini bertujuan untuk menyeimbangan area hijau dan area terbangun pada tapak. Hasil yang didapatkan berupa tanaman hijau yang berada di sekitar tapak jumlahnya tidak banyak, hanya 
berada di sekeliling waduk, lalu pada tapak kosong di belakang tapak perancangan, dan di tapak Thamrin Residence, sehingga pada proyek nanti akan dirancang pembangunan area hijau yang maksimal di dalam tapak. Lalu analisa kebisingan disesuaikan dengan proyek kantor yang sekiranya memiliki kebutuhan privat dari kebisingan sekitar tapak, namun setelah dianalisa maka hasilnya berupa kebisingan yang tidak mengganggu dan hanya bersumber dari kendaraan yang lewat dan perumahan.

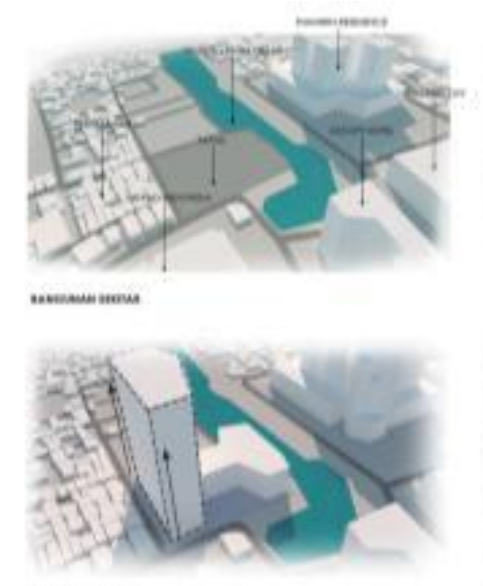

newas ans

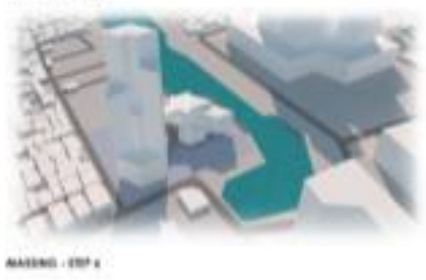

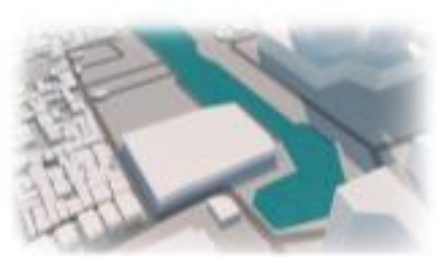
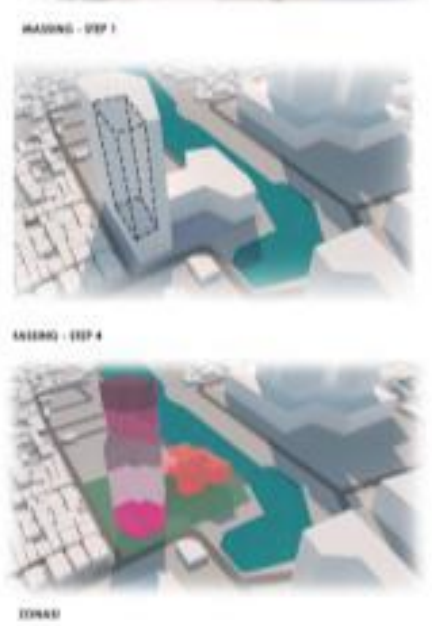

Gambar 8. Skema Desain Sumber: Penulis, 2019
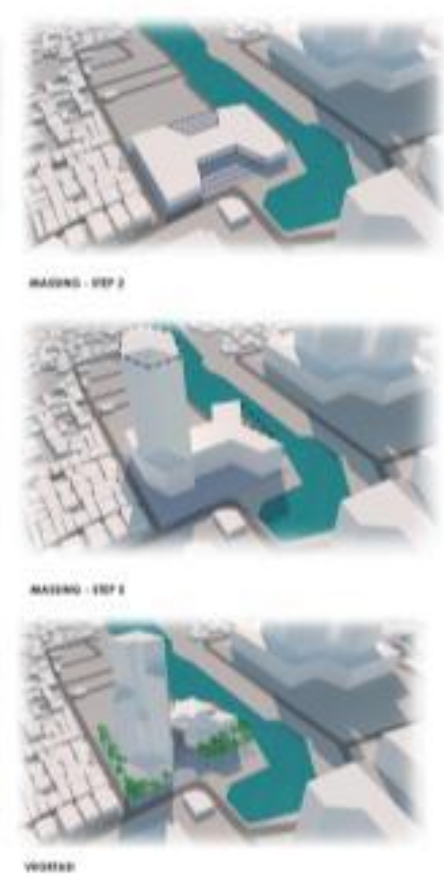

mens:

Pada Gambar 8 digambarkan proses gubahan massa. Gambar ini merupakan design scheme yang berisi gubahan massa bangunan setelah disesuaikan dengan bentuk tapak dan juga disesuaikan dari hasil analisa kawasan dan tapak yang sebelumnya dilakukan.

Setelah melalui proses perancangan yang diawali dengan pemahaman teori dan dilanjutkan dengan metode tipologi dan analisa kawasan serta tapak, maka dihasilkan bangunan dengan sistem mixed use atau multifungsi dengan tiga program utama, yaitu kantor sewa, co-working space, dan penunjang. Bangunan ini memiliki wujud high-rise 30 lantai termaksud podium 6 lantai dan 2 lantai basement. Bentuk fasade yang dihasilkan pada gubahan massa terbentuk setelah analisa tapak, dan disesuaikan dengan konsep monumental, sehingga massa bangunan tidak sama seperti bangunan yang disekitar tapak. Selain itu, penyusunan ruang dan pemilihan material pada tiap ruang disesuaikan dengan generasi millenial. Hal ini dapat dilihat pada Gambar 9. 


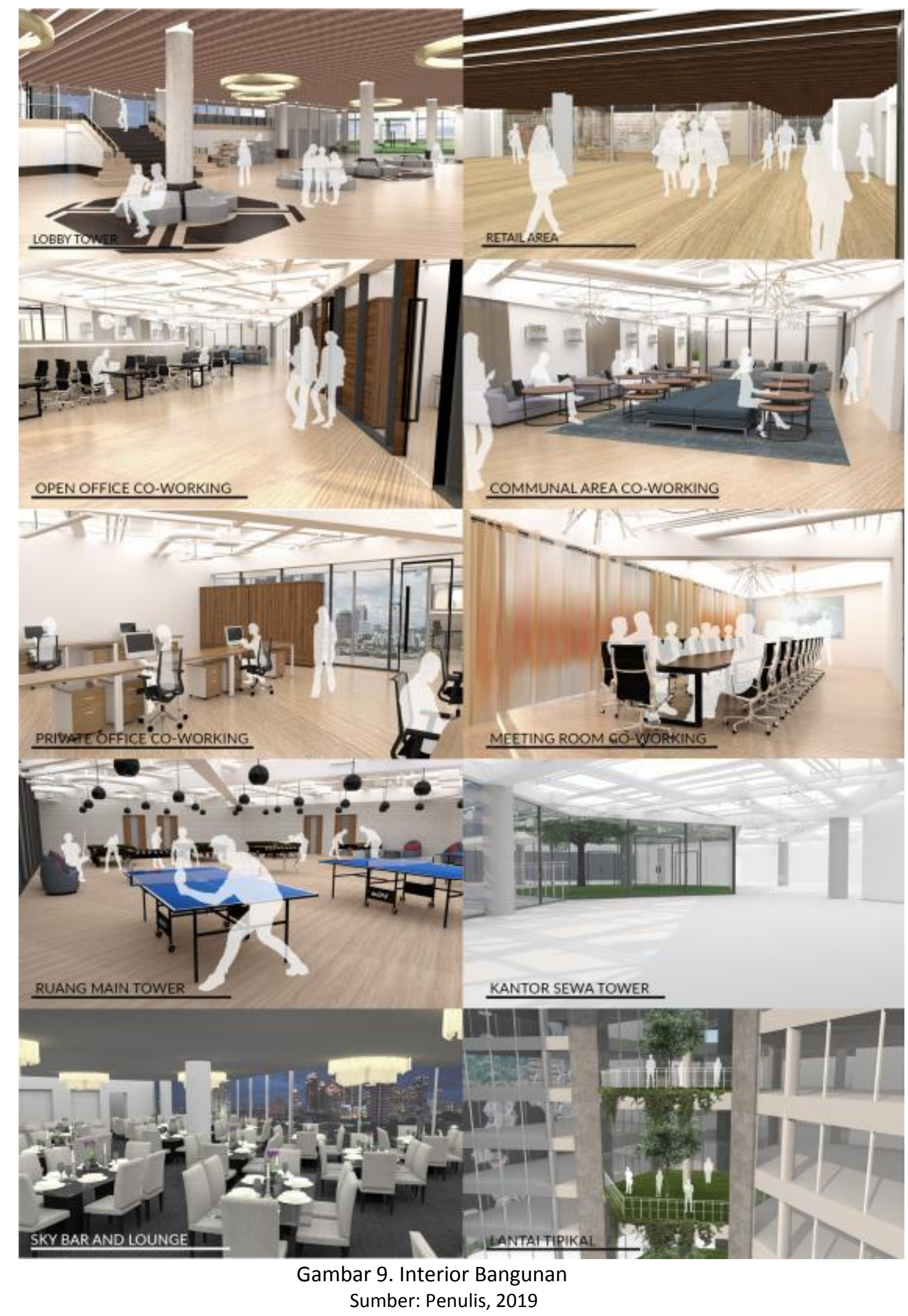




\section{KESIMPULAN DAN SARAN}

Disimpulkan bahwa proyek Tanah Abang Mixed Use Office Building atau Bangunan Kantor Multifungsi di Tanah Abang ini dengan ketinggian 30 lantai dan desain yang kontekstual atau ikonik didesain sebagai tempat bekerja paling efektif bagi generasi millenial. Baik perusahaan yang sudah terbangun ataupun perusahaan start up. Proyek ini juga mampu menampung segala jenis perusahaan, khususnya yang bergerak di bidang IT atau social media developer. Selain itu disediakan pula program penunjang sebagai penyeimbang antara tapak dengan kawasan, sehingga pengunjung juga bisa datang dan tidak hanya diperuntukkan bagi penyewa.

Disarankan pada proses perancangan sebuah bangunan arsitektur, khususnya untuk proyek yang kali ini akan dirancangan sebaiknya memperhatikan beberapa hal, seperti efisiensi ruang dan saleable area. Dimana dalam sebuah desain yang tidak biasa akan memiliki kesulitan pada penataan ruang yang nantinya akan terbayar pada pengalaman ruang yang berbeda pula. Bentuk tersebut juga akan menentukan penggunaan struktur core yang tidak seperti biasanya.

\section{REFERENSI}

Advice, C. (2018, September 10). Inilah Kriteria Kantor Idaman Kaum Millennials.

Alexander, C. (1977). A Pattern language.

Gallup. (2016). How Millennials Want to Work and Live.

Kliment, S. A. (2002). Office Buildings.

Manasseh, L. And R. Cunliffe. (1962). Office Buildings.

Ristawan, I. K. (2018). Tugas Mata Kuliah Metode dan Pendekatan Perancangan: Resume Materi Perkuliahan Tipologi of Design Method

Warner, L. (2002). Out at Work. https://www.urbanhire.com/blog/inilah-kriteria-kantoridaman-kaum-millennials/

Basulto, D. (2008, May 3). Bryghusgrunden mixed use, Copenhagen / OMA. Retrieved from https://www.archdaily.com/207/bryghusgrunden-mixed-use-copenhagen-denmaroma/?ad source=myarchdaily\&ad_medium=bookmark-show\&ad_content=current-user

Plowright, P. D. (2017). Revealing Architectural Design Methods, Frameworks, and Tools.

Santibanez, D. (2019, January 11). Torre Diana / Colonnier y Asociados. Retrieved from https://www.archdaily.com/907901/torre-diana-colonnier-yasociados/?ad_source=myarchdaily\&ad_medium=bookmarkshow\&ad_content=current-user

Rahmi, A. (2018, Mei 16). Millennial 2 Kali Lebih Stress Karena Pekerjaan, Ini Penyebabnya. Retrieved from https://wolipop.detik.com/work-and-money/d-4022070/millennial-2kali-lebih-stres-karena-pekerjaan-ini-penyebabnya 